\title{
Functional outcome and general health status in patients after arthroscopic release in adhesive capsulitis
}

\author{
M. H. Baums · G. Spahn · M. Nozaki · H. Steckel • \\ W. Schultz $\cdot$ H.-M. Klinger
}

Published online: 17 March 2007

(C) Springer-Verlag 2007

\section{Erratum to: Knee Surg Sports Traumatol Arthrosc DOI 10.1007/s00167-006-0203-x}

Unfortunately, the first sentence in the "Methods" section had been given incorrectly. It should read as follows:

Between April 1999 and February 2002, 30 consecutive patients with idiopathic adhesive capsulitis were treated arthroscopically and then evaluated prospectively by one observer.

The online version of the original article can be found at http:// dx.doi.org/10.1007/s00167-006-0203-x.

M. H. Baums $(\bowtie) \cdot$ W. Schultz $\cdot$ H.-M.Klinger Department of Orthopaedic Surgery,

Georg-August-University of Göttingen,

Robert-Koch-Str. 40, 37075 Göttingen, Germany

e-mail: mike.baums@freenet.de

\section{G. Spahn}

Center of Arthroscopy and Joint Surgery Eisenach,

Eisenach, Germany

M. Nozaki · H. Steckel

Department of Orthopaedic Surgery,

University of Pittsburgh, Pittsburgh, PA, USA 